The University of Maine

DigitalCommons@UMaine

Publications

Senator George J. Mitchell Center for Sustainability

Solutions

$3-2010$

\title{
Does a property-specific environmental health risk create a "neighborhood" housing price stigma? Arsenic in private well water
}

Kevin Boyle

Nicolai Kuminoff

Congwen Zhang

Michael Devanney

Kathleen Bell

University of Maine

Follow this and additional works at: https://digitalcommons.library.umaine.edu/ mitchellcenter_pubs

Part of the Behavioral Economics Commons

\section{Repository Citation}

Boyle, Kevin; Kuminoff, Nicolai; Zhang, Congwen; Devanney, Michael; and Bell, Kathleen, "Does a property-specific environmental health risk create a "neighborhood" housing price stigma? Arsenic in private well water" (2010). Publications. 50.

https://digitalcommons.library.umaine.edu/mitchellcenter_pubs/50 


\title{
Does a property-specific environmental health risk create a "neighborhood" housing price stigma? Arsenic in private well water
}

\author{
Kevin J. Boyle, ${ }^{1}$ Nicolai V. Kuminoff, ${ }^{2}$ Congwen Zhang, ${ }^{1}$ Michael Devanney, ${ }^{3}$ \\ and Kathleen P. Bell ${ }^{4}$ \\ Received 2 April 2009; revised 1 September 2009; accepted 23 October 2009; published 9 March 2010.
}

[1] This paper examines the impact of arsenic contamination of groundwater on sale prices of residential properties and bare land transactions in two Maine towns, Buxton and Hollis, that rely on private wells to supply their drinking water. Prompted by tests of well water by the state of Maine, media attention focused on the communities in 1993 and 1994 when $14 \%$ of private wells were found to have arsenic concentrations exceeding the U.S. Environmental Protection Agency standard of $0.05 \mathrm{mg} / \mathrm{L}$. Households could mitigate the serious health risks associated with arsenic ingestion by purchasing bottled water or by installing a reverse osmosis home treatment system. Our results indicate that the initial arsenic finding in 1993 led to significant, but temporary, 2 year decreases in property prices. This is a much shorter effect on prices than has been observed for Superfund sites, where prices can be depressed for a decade. These results suggest that a property-specific contamination incident that is treatable may not have a long-lasting effect on sale prices, but further research is needed to confirm if the dissipation of the price effect was actually due to the installation of in-home water treatment systems or due to the dissipation of perceived risk once the media coverage stopped.

Citation: Boyle, K. J., N. V. Kuminoff, C. Zhang, M. Devanney, and K. P. Bell (2010), Does a property-specific environmental health risk create a "neighborhood" housing price stigma? Arsenic in private well water, Water Resour. Res., 46, W03507, doi:10.1029/2009WR008074.

\section{Introduction}

[2] Arsenic in drinking water is a global problem. Argentina, Australia, Bangladesh, Chile, China, Hungary, India, Mexico, Peru, Thailand, and the United States all have areas with arsenic concentrations above the recommended maximum contaminant level for drinking water [World Health Organization (WHO), 2001]. In many of these countries a large share of the population is affected. For example, arsenic contamination of groundwater in Bangladesh has put between 46 and 57 million of the 130 million inhabitants at risk [WHO, 2001]. In the United States, arsenic can pose a serious concern for homes on private well water in areas with high levels of naturally occurring arsenic.

[3] Long-term exposure to drinking water with concentrations of arsenic above $0.05 \mathrm{mg} / \mathrm{L}$ can cause severe health risks. The most severe risks associated with chronic ingestion of arsenic in drinking water include developing skin, bladder, and lung cancers [U.S. Environmental

\footnotetext{
${ }^{1}$ Department of Agricultural and Applied Economics, Virginia Polytechnic Institute and State University, Blacksburg, Virginia, USA.

${ }^{2}$ Department of Economics, Arizona State University, Tempe, Arizona, USA.

${ }^{3}$ Nova Scotia Department of Agriculture, Truro, Nova Scotia, Canada.

${ }^{4}$ School of Economics, University of Maine, Orono, Maine, USA.

Copyright 2010 by the American Geophysical Union. 0043-1397/10/2009WR008074\$09.00
}

Protection Agency (EPA), 2001; WHO, 2001; Smith et al., 1999]. A study by Smith et al. [1998] estimated that between $7 \%$ and $10 \%$ of all adult deaths in Chile between 1989 and 1993 were due to bladder and lung cancers attributable to arsenic exposure. Exposure to arsenic has also been shown to cause blood vessel damage, changes in skin pigmentation, and hyperkeratosis (thickening of the outer skin layer) [WHO, 2001]. Additionally, low-level exposure to arsenic in drinking water $(0.01$ to $0.02 \mathrm{mg} / \mathrm{L})$ may lead to an increased risk of depression, while exposure to arsenic concentrations above $0.01 \mathrm{mg} / \mathrm{L}$ leads to a significantly higher risk of high blood pressure, circulatory problems and the need for cardiac bypass surgery [Zierold et al., 2004].

[4] In response to growing concern about the adverse health effects of chronic arsenic ingestion, the EPA lowered the maximum contaminant level (MCL) for arsenic concentrations in public water systems from $0.05 \mathrm{mg} / \mathrm{L}$ to $0.01 \mathrm{mg} / \mathrm{L}[E P A, 2001]$. This new standard took effect in January 2006.

[5] When revising the MCL standard the EPA estimated that as many as 12.8 million people are exposed to arsenic concentrations in excess of $0.01 \mathrm{mg} / \mathrm{L}$ in drinking water supplied by public water systems $[E P A, 2001]$. The new arsenic standard aids in mitigating adverse health effects for the people who rely on these systems for their drinking water. Suburban and rural residents who rely on private wells for their drinking water, however, must choose to have their tap water tested for the presence of arsenic and must pay to have private treatment systems installed in their 


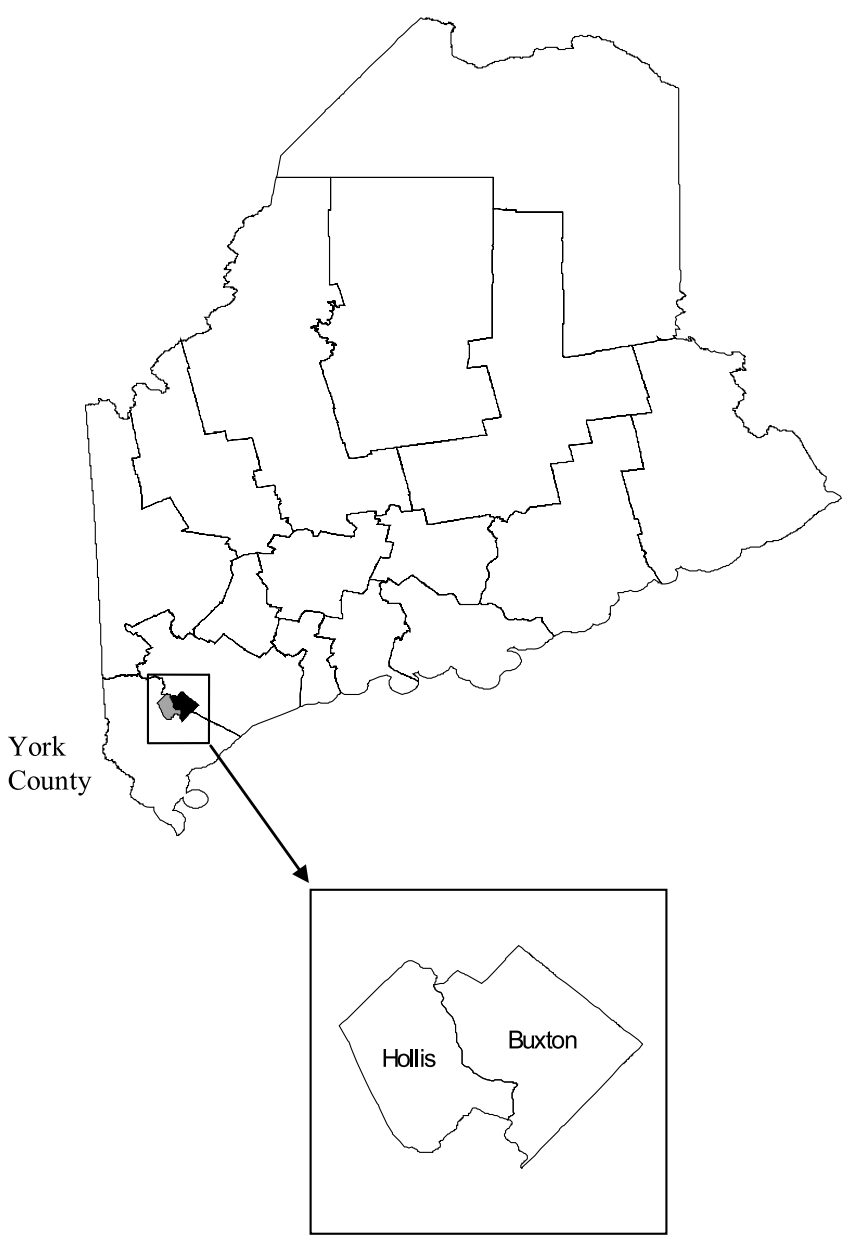

Figure 1. The towns of Buxton and Hollis, located in York County, Maine. Buxton is located at $43^{\circ} 38^{\prime} 7^{\prime \prime} \mathrm{N}, 70^{\circ} 32^{\prime} 21^{\prime \prime} \mathrm{W}$, and Hollis is located at $43^{\circ} 38^{\prime} 5^{\prime \prime} \mathrm{N}, 70^{\circ} 37^{\prime} 15^{\prime \prime} \mathrm{W}$.

homes if the test result indicates an arsenic concentration that is unsafe.

[6] This paper examines the impact of arsenic contamination of private well water on sale prices of single-family, residential properties and bare land transactions (potentially developable for residences) in two Maine towns where arsenic contamination has been well documented, Buxton and Hollis. Maine is the northeastern most state in the United States, located along the Canadian border. Figure 1 shows the locations of Buxton and Hollis, located next to each other in York County in the southwestern part of Maine. Media attention focused on these communities in the early 1990s when well water tests exhibited arsenic concentrations above the EPA standard, at that time, of $0.05 \mathrm{mg} / \mathrm{L}$ [Maine Geological Survey, 2005]. All households in these communities rely on private wells to supply their drinking water; there are no public drinking water systems. A study by Marvinney et al. [1994] found that $14 \%$ of private wells in Buxton and Hollis exceeded the (pre-2006) EPA standard for arsenic of $0.05 \mathrm{mg} / \mathrm{L}$.

[7] Buxton and Hollis were the first communities in Maine to have documented arsenic contamination of well water. Prior to this event arsenic contamination was not something that homeowners would have been likely to consider and there were no other known contaminants in well water in this area. We investigate whether knowledge of arsenic in groundwater, and consequently drinking water, depressed sale prices of houses in Buxton and Hollis, Maine, and test whether this price effect dissipated through time as residents may have installed private treatment systems in their homes.

\section{Previous Research}

[8] Economic analysis of health effects of arsenic contamination of drinking water is a subject that has received little attention. Estimation of the economic benefits of avoiding arsenic in drinking water has mostly been conducted in south Asia. Ahmad et al. [2005] found that rural Bangladesh households would pay about $0.25 \%$ of average household income for arsenic free drinking water. Maddison et al. [2005] estimated the aggregate willingness to pay to avoid arsenic health impacts in Bangladesh is $\$ 2.7$ billion annually. Roy [2008] found that households in North 24 Parganas and Midnapore, India would pay about $\$ 7$ per month for water with an arsenic concentration below $0.05 \mathrm{mg} / \mathrm{L}$.

[9] Research in the United States demonstrates that some, but not all, households in an arsenic cluster invest in self protection through averting behavior, and that home treatment systems can be cost effective. Shaw et al. [2005] found that $38 \%$ of the households in Churchill County, Nevada with private wells treat their tap [see also Walker et al., 2005, 2006]. The median concentration of arsenic in Churchill County well water is $0.26 \mathrm{mg} / \mathrm{L}$, well above the current EPA standard of $0.01 \mathrm{mg} / \mathrm{L}$. In a different area with arsenic concentrations above the MCL, Outagamie County, Wisconsin, Jakus et al. [2009] found that residents with higher perceived health risks of arsenic exposure tend to purchase more bottled water. Sargent-Michaud et al. [2006], using data from Maine, found that home water treatment systems are generally more cost effective than buying bottled water to avoid exposure to arsenic in drinking water.

[10] The results from the studies by Shaw and colleagues suggest that arsenic concentrations above the MCL in tap water may have an effect on sale prices of homes. If a potential homebuyer knows that a home water treatment system needs to be installed to protect their families' health from arsenic concentrations, this knowledge should reduce the price they would be willing to pay for a home that has an arsenic concentration above the MCL in the tap water and does not have a treatment system installed. However, Walker et al. [2005, p. 305] also speculate that the $62 \%$ of households who do not treat their tap water do "...not recognize that consumption could have associate health risks," which would hinder the ability to estimate any price effect from the presence of arsenic in tap water.

[11] No studies, to our knowledge, have investigated the relationship between sale prices of residential properties and arsenic contamination, and few studies have investigated the relationship between sales prices and health risks from consumption of contaminated tap water. We identified one study that investigated the relationship between nitrate contamination of groundwater and sale prices of residential properties in Portage County, Wisconsin [Malone and Barrows, 1990]. They found that nitrate contamination of groundwater did not affect sale prices. The health conse- 


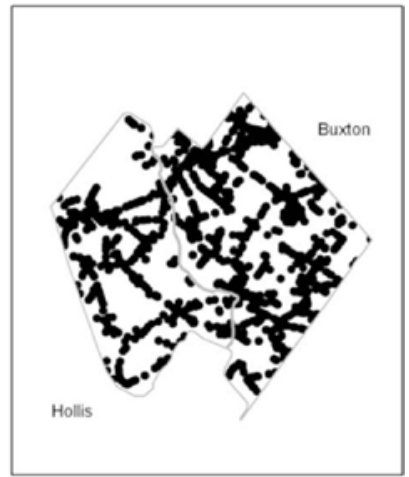

All Arsenic Tests

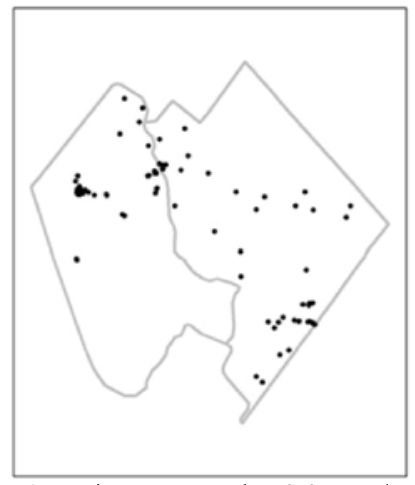

Arsenic Test Level $>0.05 \mathrm{mg} / \mathrm{L}$
Figure 2. Geographic distribution of arsenic tests.

quence of consuming water with nitrate contamination is blue baby syndrome, which is not fatal. The health consequences of arsenic are more severe and one might expect arsenic contamination to be more likely to impact sale prices than nitrate contamination.

[12] The vast majority of hedonic studies that have investigated the effects of water quality on sale prices of residential properties have focused on contamination of surface waters that are not used as drinking water supplies [see Boyle and Kiel, 2001, exhibit 2, p. 124]. These studies have focused almost exclusively on the recreational and/or aesthetic aspects of water quality as they pertain to property values. They have demonstrated significant suppression of sale prices for a wide variety of surface water contamination events.

[13] There have also been a number of hedonic property value studies that have investigated the relationship between sale prices and proximity to undesirable land (e.g., Superfund or hazardous waste disposal sites) uses where one of the consequences is groundwater contamination [see Boyle and Kiel, 2001, exhibit 3, pp. 127-130]. These studies have generally used proximity to the undesirable land use as the key environmental variable in their hedonic price functions, which makes it impossible to identify a groundwaterspecific effect. One of these studies [Kiel, 1995] considered an application where there was known groundwater contamination from two nearby Superfund sites. These were sites that had been in industrial use since the mid-1800s and groundwater contamination was accompanied by contaminated soils and unpleasant odors. Even though safe drinking water was provided to nearby households while U.S. EPA administered cleanup was undertaken at the contaminated sites, Kiel found that housing prices had been stigmatized. For example, during the year that cleanup efforts began, she estimated that property values increased by approximately $\$ 6,500$ per mile of distance from the Superfund sites. Messer et al. [2006], using up to 30 years of data for one contamination site, found that stigmas on residential property may result in sale prices taking 5-10 years to recover after the contamination has been cleaned up.

[14] Stated-preference studies clearly indicate that people will pay for protecting and improving groundwater [see Boyle et al., 1994]. For example, Poe and Bishop [1999] found that Portage County, Wisconsin residents would pay as much as $\$ 400$ per year for a program that would improve groundwater quality for all households in the county, including their own. Stevens et al. [1997] found that households in selected western Massachusetts towns are willing to pay $\$ 16$ to $\$ 192$ per year for a home tap water treatment system.

[15] The studies cited above indicate that people do value safe drinking water. The literature indicates that some, but not all, homeowners will install private treatment systems in areas where private well water is known to be contaminated. This leaves most properties without in-home water treatment systems to protect residents' health. Even if a home treatment system is installed, home buyers may still be wary because the systems require maintenance and can fail. If there is general knowledge of groundwater contamination that is available to home buyers, one might expect potential buyers to offer less for residential properties in such an area. However, the potential to control exposure to arsenic in drinking water through in-home treatments systems suggests that the stigma would be less severe than has been observed for Superfund sites.

\section{Study Area}

[16] Public notification of arsenic contamination should have motivated home buyers to beware when buying properties in the communities of Buxton and Hollis. In the summer of 1993, residents of these two towns became concerned about arsenic concentrations (greater than $0.05 \mathrm{mg} / \mathrm{L}$ ) in the local school water supply [Marvinney et $a l ., 1994]$. This led to town-wide efforts to test for arsenic and to educate households about the potential health risks of arsenic in drinking water from private wells. Figure 2 shows the locations of 1,200 tests of well water that were conducted throughout the two towns. The spatial pattern of these tests follows the road network. In total, $13.8 \%$ of the test results revealed arsenic concentrations in violation of the $0.05 \mathrm{mg} / \mathrm{L} \mathrm{EPA} \mathrm{standard.} \mathrm{Figure} 2$ illustrates that the wells with arsenic test results greater than $0.05 \mathrm{mg} / \mathrm{L}$ are clustered in particular locations within each town.

[17] From 1993 through 2003 there were 121 articles published in Maine's two major newspapers (Bangor Daily News and Portland Press Herald) on arsenic contamination of drinking water, and 20 of these articles were published in 1993 and 1994 (K. P. Bell et al., University of Maine, unpublished data, 2008). In 1993, Buxton was the only Maine community mentioned in the articles. In 1994, both Buxton and Hollis were mentioned in the articles on arsenic contamination of well water as well as several nearby towns where residents were being advised to have their well water tested. Buxton and Hollis were not mentioned in the media articles from 1995 through 2003 as it became known that arsenic contamination of well water was a statewide problem. The newspaper articles also provided information on bottled water and home treatment systems during this time. The newspaper articles were accompanied by reporting of arsenic contamination of private well water by the television and radio news media.

[18] Households in Buxton and Hollis that were concerned about arsenic levels in their tap water could mitigate the health risks by purchasing bottled water or by installing a home treatment system [EPA, 2005]. The treatment system available to homeowners in the early 1990s was reverse osmosis, which could be installed at the 
point of use (e.g., kitchen sink) or as a whole-house system. The whole-house system was not reliable and not recommended.

[19] While potential homebuyers might have been initially alarmed when arsenic was first found in tap water, this concern could have dissipated over time as treatment systems were installed for homes with arsenic concentrations above the recommended MCL. Nevertheless, a residual price effect may have persisted because the available treatments were not perfect substitutes for purchasing a home with tap water that was safe to drink. It would have been expensive and time consuming for a household to make a complete switch from tap water to bottled water. It also would have been expensive for a household to purchase, install, and maintain a home treatment system. The recommended treatment technology was a point-of-use, reverse osmosis system. Implementing this recommendation means that only one water tap in a home would provide safe drinking water and would leave households with the inconvenience that not all water taps in the home provide safe drinking water. In addition, reverse osmosis systems can fail, which leaves households with a residual risk of exposure to arsenic if tap water was not tested regularly to identify failures. We would expect the net present value of these direct and indirect costs to be at least partly capitalized into property values. In other words, a reduced offer price for residential properties in Buxton and Hollis might have reflected the costs of installing a home treatment system or the perceived residual risk of living in an area with arsenic in well water.

\section{Conceptual Hedonic Property Value Framework}

[20] In Maine the onus is on the buyer of a property to have knowledge of potential arsenic contamination and to inquire about this risk. Sellers have a disincentive to test their well water if they anticipate selling their property. If a test is conducted, the results of the test must be revealed to the buyer, but the law does not require the seller to have the water tested [Maine Department of Professional and Financial Regulation, 2006]. When sellers have knowledge of arsenic contamination in their tap water they are likely to inform buyers if they have installed a home treatment system because they are required by law to reveal the contamination test result. A buyer can physically identify if a treatment system is in place in a home they are considering purchasing. This requires looking under the kitchen sink and at the point of entry where the water supply enters the home.

[21] While a seller must reveal any tap water test results to potential buyers, the test results for specific properties are otherwise confidential and are not available to empirical investigators. This means it is not possible to model sale prices of homes, which are public information, as a function of property-specific arsenic test results. In addition, even if arsenic test results could be linked to specific sale properties not all properties would have had an arsenic test. Buyers of such properties must make purchase decisions based on their expectations of the likelihood that the water may be contaminated with arsenic. In the absence of seller revealed information, a buyer must have knowledge of the potential for arsenic contamination of tap water and must take the initiative to request a water test. In addition, bare land sales would not have a well available for potential buyers to take a water sample. A potential source of "data" for buyers to form this expectation would be inquiries of neighbors to learn if water from existing wells in the area had concentrations of arsenic above the MCL.

[22] In-home treatment systems are also not known to an empirical investigator as tax assessors, who maintain property data, do not record this information for built properties. This is an important omitted variable as the installation of in-home treatment systems are likely correlated with the level of arsenic concentrations. More will be said about this concern in the caveats later in the paper.

[23] Arsenic contamination of groundwater in not a ubiquitous contaminant in the study area; it tends to be correlated across space. Groundwater in the study area occurs in fractured bedrock. As a result, arsenic concentrations above the MCL tend to be patchy. A level of arsenic on one property above the MCL increases the probability that a neighboring property's well water will also have an elevated level, but concentrations may drop suddenly for properties just outside of a patch. To capture the spatial correlation in arsenic levels and the fact that potential homebuyers may have imperfect information about the degree of arsenic contamination in specific wells, we model purchases of housing and bare land as a function of the buyer's perceived health risks from arsenic in the neighborhood of the sale property.

[24] Consider the following stylized argument. A household obtains utility $(U)$ from the purchase of a home $(H)$ and a composite $(G)$ of all the other goods and services it consumes:

$$
U=U(H, G)
$$

and

$$
H=H(S, L, E) \text {. }
$$

Following Lancaster's [1966] characteristics approach to consumer theory, the home $(H)$ can be decomposed into the various attributes it provides: structural $(S)$, location $(L)$, and environmental $(E)$. Arsenic contamination of groundwater, which is used as the source of drinking water, is one of the environmental attributes. The presence of an in-home treatment system for arsenic would be a structural attribute. The buyer's expected family health is, therefore, potentially affected by elements of $E$ and $S$, the perceived health risks associated with living in a neighborhood with arsenic concentrations above the MCL $\left(a_{n} \in E\right)$ and the type of home treatment device $(t r \in S)$ available to remove arsenic from tap water.

[25] Each buyer will choose a property that provides the set of attributes that maximizes utility from consumption of $H$ and $G$, given housing prices, $p$, income, $y$, and preferences for housing attributes and perceived health risks from arsenic exposure, $\alpha$. This utility maximization problem can be written formally as

$$
\max _{H, G} U(H, G ; \alpha) \text { subject to } y=G+P(H) .
$$

The endogenous perceived health risks $(\alpha)$ are based on purchasers' knowledge of potential arsenic exposure, the health consequences of exposure, and actions they can take 


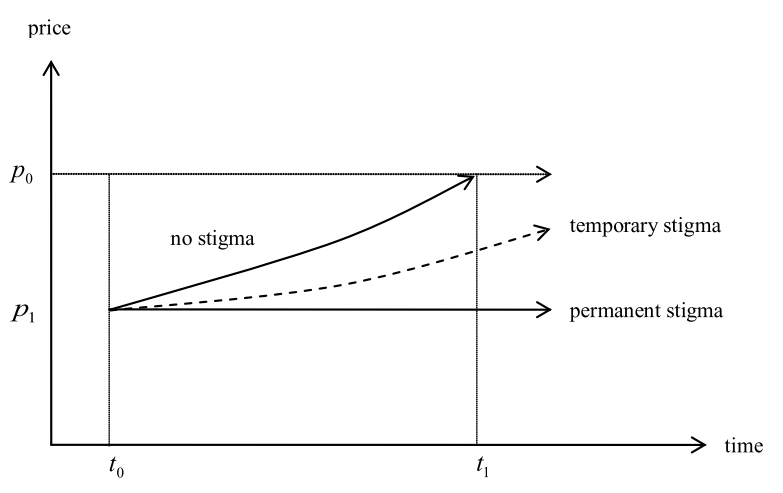

Figure 3. Arsenic "price stigma" on sale prices.

to mitigate exposure and the risks from exposure. Here, $a_{n}$ is the observed variable that would trigger a household's knowledge of arsenic in drinking water and is the only element of perceived risk that is observable in the hedonic data. Notice that the price of the composite good, $G$, has been normalized to equal 1 . Therefore, one additional unit of $G$ provides the buyer with the same utility as one additional dollar of income.

[26] Rosen [1974] demonstrated that, in a market equilibrium, the price of a differentiated good such as housing will be a function of its attributes, $P(H)=P(S, L, E)$. Moreover, he demonstrated that the partial derivative of the hedonic price function with respect to a particular attribute will measure a buyer's willingness to pay for a marginal change in that attribute. To see Rosen's result, consider the first-order condition to the utility maximization problem with respect to arsenic:

$$
\frac{\partial P(H)}{\partial a_{n}}=\frac{\partial U / a_{n}}{\partial G / \partial G}
$$

The partial derivative to the left of the equality simply measures how a small increase in neighborhood arsenic concentrations affects the market price of a home. The term to the right of the equality measures the buyer's valuation of a small change in arsenic concentrations; in other words, it measures the amount of money that the buyer would be willing to trade to avoid a small increase in $a_{n}$. Thus, by empirically estimating the equilibrium hedonic price function, $P(H)=P(S, L, E)$, and differentiating it with respect to neighborhood arsenic concentrations, we can measure how arsenic concentrations affect property values, and this property value effect should reflect buyers' valuation of the perceived health risks.

[27] Economic theory suggests that the hedonic price function is generally nonlinear [Ekeland et al., 2004]. Yet, most empirical hedonic studies treat linearity as a maintained assumption. This follows from Cropper et al.'s [1988] Monte Carlo analysis of how the accuracy in predicting the marginal willingness to pay for a housing characteristic varies across competing functional form assumptions. They find that simpler parametric specifications for the price function (such as the log linear and log-log functional forms) outperform more flexible specifications in the presence of omitted variables. Therefore, adopting a simple functional form can help to hedge against the risk of omitted variable bias.

[28] We estimate the following log linear equilibrium hedonic price function for the local land market:

$$
\ln (p)=f(S, L, A, t)
$$

where $A$ is a vector of arsenic variables and $t$ is a vector of dummy variables that denote each year of sales data. Here, arsenic is the sole environmental characteristic in the price function because there were no other known contaminants of groundwater in the study area over the time period we investigate. The presence of arsenic in groundwater is highly unlikely to be correlated with any terrestrial environmental amenities or disamenities, which implies that the omission of such variables from this specification will not bias estimated arsenic coefficients. We will clarify this point in the caveats below. The vector of arsenic variables can be defined as follows:

$$
A=A\left(a_{n}, a_{n} \cdot t\right) .
$$

This specification allows us to test whether arsenic concentrations in well water above the MCL create a neighborhood price stigma and whether this stigma increases or dissipates through time.

[29] Figure 3 presents several possible stigma effects. Prior to any arsenic findings, the average property value in a neighborhood is $p_{0}$. In year $t_{0}$ people learn that well water in the neighborhood is contaminated with arsenic. This decreases the demand for housing in the neighborhood, decreasing the average property value from $p_{0}$ to $p_{1}$. In the following years, homeowners with arsenic concentrations above the MCL install water treatment systems so that all homes with elevated arsenic use treated water by year $t_{1}$. If the stigma is permanent, property values will never rebound; they will remain at $p_{1}$ despite the fact that water treatment mitigates the health risk. In a linear parameterization of equation (6), this would imply a negative coefficient on $a_{n}$ and zero coefficients on all of the interaction effects; the initial arsenic finding permanently depresses prices. At the opposite extreme, if there is no stigma, property values return to their initial levels by $t_{1}$. An intermediate case between these two extremes is suggested by McCluskey and Rausser [2003]. To use their terminology, a "temporarydeclining stigma" may arise if potential homebuyers are still wary about the possibility of arsenic contamination even after the problem has been mitigated. Such a case could arise due to initial concerns that in-home treatments systems might fail and such concerns dissipating through time as homeowners develop more experience with the systems. This situation could be represented in a linear parameterization of equation (6) by a zero coefficient on $a_{n}$, and negative coefficients on the interaction effects that decline in magnitude over time, but do not reach zero by year $t_{1}$.

\section{Data}

[30] Data were collected for single-family and bare land property sales between 1992 and 2003 in the towns of Buxton and Hollis, Maine. The data range was selected because 1992 is the year before arsenic in groundwater became public knowledge in these towns. Sales records in the Town of Hollis were missing for 1992. 
Table 1. Descriptive Statistics

\begin{tabular}{lccccc}
\hline & \multicolumn{2}{c}{ Buxton $^{\mathrm{a}}$} & & \multicolumn{2}{c}{ Hollis $^{\mathrm{b}}$} \\
\cline { 2 - 3 } \cline { 5 - 6 } & Mean & SD & & Mean & SD \\
\hline SALEPRICE & 91,015 & 60,410 & 97,681 & 61,334 \\
ln(PRICE) & 11.12 & 0.90 & 11.21 & 0.88 \\
IMPROVED & 0.78 & 0.41 & & 0.82 & 0.38 \\
SQFT*IMPROVED & 728.90 & 446.12 & & 769.19 & 460.08 \\
AGE*IMPROVED & 36.21 & 53.35 & & 40.55 & 54.06 \\
ACRES & 4.56 & 9.55 & & 5.67 & 16.87 \\
AS $>0.05(p p b)$ & $c$ & & & & \\
t1992 & 86.36 & 28.07 & & 93.33 & 59.95 \\
t1993 & 0.05 & 0.21 & & NA & NA \\
t1994 & 0.07 & 0.26 & & 0.05 & 0.21 \\
t1995 & 0.07 & 0.26 & & 0.06 & 0.23 \\
t1996 & 0.07 & 0.25 & & 0.09 & 0.29 \\
t1997 & 0.08 & 0.27 & & 0.09 & 0.29 \\
t1998 & 0.09 & 0.29 & & 0.09 & 0.28 \\
t1999 & 0.10 & 0.29 & & 0.11 & 0.32 \\
t2000 & 0.10 & 0.30 & & 0.12 & 0.33 \\
t2001 & 0.11 & 0.31 & 0.11 & 0.32 \\
t2002 & 0.09 & 0.29 & 0.03 & 0.16 \\
t2003 & 0.09 & 0.29 & 0.12 & 0.33 \\
\hline
\end{tabular}

${ }^{\mathrm{a}}$ For Buxton, $\mathrm{n}=1,669$. SD is standard deviation.

${ }^{\mathrm{b}}$ For Hollis, $\mathrm{n}=542$. SD is standard deviation.

${ }^{\mathrm{c}}$ Arsenic Concentrations measured in parts per billion (ppb), $50 \mathrm{ppb}=$ $>0.05 \mathrm{mg} / \mathrm{L}$.

${ }^{\mathrm{d}}$ No sales data were available for Hollis for 1992

[31] These towns are largely "bedroom" communities located in York County, approximately 20 miles west of Portland, the largest city in the state. Data collected from town offices include the actual sale price of each property sold during the study period and the characteristics of the homes built on those properties. These residences were mostly built long before arsenic was discovered in the early 1990s (the average structure is approximately 50 years old). The housing data include structural characteristics of each home (square footage of living space and age of structure) and the land characteristics of each property (acreage of lot). A parsimonious set of explanatory variables is employed because of inconsistent reporting of house structure and land characteristics in the property tax data. Including additional structural and land variables would have substantially reduced the usable sample sizes.

[32] GIS data on private well arsenic concentrations were obtained from the Maine Geological Survey. While these data allowed us to construct "neighborhood" based measures of arsenic test results, they could not be linked to individual properties. More precisely, the arsenic measure we attached to each home is the level of the nearest test result to exceed the EPA standard of $0.05 \mathrm{mg} / \mathrm{L}$. Recall that during the time frame that property sales are examined, 1992 through 2003, the EPA standard (MCL) for arsenic was $0.05 \mathrm{mg} / \mathrm{L}$. All households in the Buxton/Hollis area were provided with printed information from the state of Maine's toxicologist that tap water with arsenic concentrations in excess of $0.05 \mathrm{mg} / \mathrm{L}$ was not safe to drink and posed health risks, including cancer.

[33] Various alternative measures of "neighborhood" arsenic levels were also considered including the arsenic level of the nearest test result to each sold property, the average arsenic level of test results greater than $0.05 \mathrm{mg} / \mathrm{L}$ for tests within one quarter mile of each sold property, and the average arsenic level of test results that is greater than $0.05 \mathrm{mg} / \mathrm{L}$ for tests within one half mile of each sold property. These and other specifications do not substantially change the results reported below. In general, the more distant a test result is to a property the less likely it is to have a price effect.

[34] To estimate the effect of arsenic contamination on property values in the study area, the natural log of the sales price of a property was regressed on the following variables: IMPROVED, equals 1 if a property includes a house and zero otherwise; SQFT*IMPROVED, square feet of living space in-house multiplied by IMPROVED; AGE*IMPROVED, age of the house multiplied by IMPROVED; ACRES, lot size in acres; $t_{i}$, a series of indicator variables that equal 1 for each study year $(i)$ and 0 otherwise (2003 is the omitted category); $a_{n}$, arsenic concentration of nearest test result in excess of $0.05 \mathrm{mg} / \mathrm{L}$ (coded as parts per billion $(\mathrm{ppb})(50 \mathrm{ppb}=$ $>0.05 \mathrm{mg} / \mathrm{L}$ ); and $a_{n}{ }^{*} t_{i}$. Table 1 reports descriptive statistics for these variables.

[35] The year indicator variables deserve some explanation. Given the semilog form of the price function in equation (5), adding the year indicators allows sale prices to adjust by a different percentage each year. This controls for inflation by effectively deflating sale prices, while simultaneously capturing year-to-year variation in the data due to unobserved market factors that are not related to the characteristics of individual properties. If the location of a new business were to create new jobs in Buxton and Hollis, for example, the year indicators would absorb the subsequent percentage change in property values. The year indicators also serve to control for the local effects of national market trends, particularly the housing market boom that began in the late 1990s and the brief recession that occurred in 2001 .

\section{Results}

[36] The parsimonious set of explanatory variables underscores the importance of controlling for spatial correlation in the unobserved characteristics of houses and neighborhoods. If the prices of homes in a neighborhood are correlated because they share similar design features that are observed by buyers, but not by the researcher, then this correlation can bias the standard errors from ordinary least squares (OLS) estimation. This potential problem can be addressed by testing to detect if a pattern of spatial correlation exists in the residuals from OLS estimation and then adjusting the standard errors accordingly [Anselin, 1988, 2002].

[37] One of the standard test statistics used to detect the presence of spatial correlation is Moran's I. A positive value indicates that the OLS residuals are positively correlated. We found positive Moran's I statistics that were significant in separate regressions for Buxton and Hollis. The $p$ value for Moran's I was 0.001 for a regression using the Hollis data and 0.00001 for a regression using the Buxton data. Given the presence of spatial correlation, we investigated whether the data are best explained by correlation in the dependent variable (a spatial lag model) or by correlation in the error terms (a spatial error model). This was done using a series of Lagrange multiplier (LM) tests, following the approach suggested by Anselin [2002]. For each of the towns, LM tests failed to reject both the spatial lag model and the spatial error model. However, robust LM tests strongly suggested the spatial error model over the spatial 
Table 2. Estimated Hedonic Price Equations ${ }^{\mathrm{a}}$

\begin{tabular}{|c|c|c|c|}
\hline Variable & Buxton & Hollis & Pooled \\
\hline IMPROVED & $0.8342 * * *(0.0920)$ & $0.9633 * * *(0.1340)$ & $0.8712 * * *(0.0752)$ \\
\hline ACRE & $-0.0019(0.0020)$ & 0.0007 (0.0018) & $-0.0004(0.0013)$ \\
\hline SQFT*IMP & $0.0003 * * *(0.0001)$ & $0.0003 * * *(0.0001)$ & $0.0003 * * *(0.0001)$ \\
\hline AGE*IMP & $-0.0004(0.0004)$ & $-0.0006(0.0007)$ & $-0.0004(0.0003)$ \\
\hline$a_{n}$ & $0.0019(0.0021)$ & $0.0007(0.0013)$ & $0.0012(0.0011)$ \\
\hline $\mathrm{T} 1992 * a_{n}$ & $0.0016(0.0038)$ & & $0.0022(0.0034)$ \\
\hline $\mathrm{T} 1993 * a_{n}$ & $-0.0105 * * *(0.0032)$ & $0.0009(0.0026)$ & $0.0011(0.0026)$ \\
\hline $\mathrm{T} 1994 * a_{n}$ & $-0.0066 * *(0.0033)$ & $0.0004(0.0018)$ & $0.0001(0.0019)$ \\
\hline $\mathrm{T} 1995 * a_{n}$ & $-0.0025(0.0036)$ & $-0.0055(0.0024)^{* *}$ & $-0.0060(0.0025)^{* *}$ \\
\hline T1993* $a_{n} *$ Buxton & & & $-0.0110(0.0034)^{* * *}$ \\
\hline T1994* $a_{n} *$ Buxton & & & $-0.0059(0.0030)^{* *}$ \\
\hline T1995* $a_{n} *$ Buxton & & & $0.0042(0.0037)$ \\
\hline T1996* $a_{n}$ & $-0.0004(0.0033)$ & $-0.0011(0.0018)$ & $-0.0011(0.0017)$ \\
\hline $\mathrm{T} 1997 * a_{n}$ & $-0.0027(0.0031)$ & $0.0011(0.0016)$ & $0.0003(0.0015)$ \\
\hline $\mathrm{T} 1998 * a_{n}$ & $-0.0014(0.0030)$ & $0.0014(0.0023)$ & $0.0002(0.0019)$ \\
\hline $\mathrm{T} 1999 * a_{n}$ & $-0.0003(0.0030)$ & $0.0002(0.0021)$ & $0.0000(0.0018)$ \\
\hline $\mathrm{T} 2000 * a_{n}$ & $-0.0002(0.0027)$ & $0.0007(0.0023)$ & $0.0006(0.0017)$ \\
\hline $\mathrm{T} 2001 * a_{n}$ & $-0.0012(0.0028)$ & $0.0079(0.0159)$ & $-0.0001(0.0021)$ \\
\hline $\mathrm{T} 2002 * a_{n}$ & $-0.0033(0.0028)$ & $0.0026(0.0024)$ & $-0.0008(0.0018)$ \\
\hline Constant & $10.5794 * * *(0.2014)$ & $10.6439 * * *(0.1597)$ & $10.6273 * * *(0.1178)$ \\
\hline$\lambda$ & $0.3529 * * *(0.1064)$ & $0.2458 * * *(0.0822)$ & $0.3812 * * *(0.0793)$ \\
\hline $\mathrm{R}^{2}$ & 0.3310 & 0.3970 & 0.3450 \\
\hline $\mathrm{N}$ & 1669 & 542 & 2211 \\
\hline
\end{tabular}

${ }^{\mathrm{a}}$ Three asterisks denote significance at the 0.01 level; two asterisks denote significance at the 0.05 level, and one asterisk denotes significance at the 0.1 level. Standard errors are in parentheses. All regressions include dummy variables for the sale year.

lag model. Therefore, we estimated spatial error models. The spatial weights matrix takes a dichotomous form where all "neighbors" are assigned a value of 1 and all "nonneighbors" are assigned a value of 0 . The distances used to define neighbors were the minimum distances such that each property had at least one neighbor.

[38] The first two columns of Table 2 report the results from spatial error models that were estimated for Buxton and Hollis individually. The positive and statistically significant coefficients on IMPROVED indicate that, as we would expect, properties with homes have much higher sale prices than those without, and sale prices for properties with homes are increasing in the size of the home (SQFT*IMP). While properties with older homes tend to be less expensive (AGE*IMP), this result is not statistically significant. Likewise, lot size (ACRE) does not have a statistically significant effect on prices. The $\lambda$ parameter measures the degree of spatial correlation in the residuals to the model; the significant, positive values for Buxton and Hollis indicate that nearby properties tend to share similar features.

[39] By interacting the neighborhood arsenic measure $\left(a_{n}\right)$ with dummy variables for each year $\left(\mathrm{T} 1992 * a_{n}, \ldots\right.$, T2002* $a_{n}$ ) the empirical hedonic model allows us to measure the extent that property values are affected by arsenic concentrations in excess of the MCL over time. Since the interaction dummy is excluded for the last year of our data (2003), the coefficient on $a_{n}$ measures the price effect of arsenic in 2003. It is not statistically different from zero for either town, indicating that any property price effect from the initial arsenic findings in 1993 had disappeared 10 years later. This implies that there is not a permanent stigma.

[40] The interaction coefficient for 1992 is also effectively zero for the Buxton data, as we would expect. This finding provides a consistency check on our model since people did not learn about arsenic in well water until the following year.
[41] After people learned about the arsenic findings, there were temporary price effects in each town that disappeared with time. All else constant, the prices of properties located in neighborhoods with arsenic readings above $0.05 \mathrm{mg} / \mathrm{L}$ dropped significantly in 1993 and 1994 for Buxton and dropped significantly in 1995 for Hollis. The interaction coefficient for Buxton in $1993(-0.0105)$ implies that a $0.01 \mathrm{mg} / \mathrm{L}$ increase in neighborhood arsenic test readings above the EPA standard temporarily decreased the resale value of a property by approximately $1 \%$. The size of this effect decreased to $0.7 \%$ in 1994 and was not statistically different from zero thereafter. For the town of Hollis, we find no statistically significant effects in 1993 and 1994, before prices dropped in 1995. The coefficient on T1995* $a_{n}$ implies that prices in Hollis dropped by approximately $0.6 \%$ per $0.01 \mathrm{mg} / \mathrm{L}$ increase in neighborhood arsenic, similar to the 1994 decrease in Buxton.

[42] A likely explanation for why the price effects for the two towns are staggered over time is that Buxton is where the school drinking water was found to have arsenic in 1993 so concern may have been more immediate in this community. Furthermore, Buxton was the only town mentioned in the stream of newspaper articles published in 1993. Hollis was mentioned in some of the articles published the following year. Since it may have taken some time for this information to be absorbed by potential homebuyers, it makes sense that prices in Hollis would have gone down in 1995. After 1995, some of the interaction coefficients in Table 2 are still negative, but none are statistically different from zero. Thus, the property price effect of the initial arsenic finding in 1993 and the subsequent news stories in 1993 and 1994 appears to have mostly disappeared by 1996 .

\section{Caveats and Robustness Checks}

[43] There are three important caveats to our econometric results. First, is our assumption that the true shape of the 
equilibrium hedonic price function is log linear. As discussed earlier, Cropper et al. [1988] found that log linear and log-log specifications for the price function outperformed more flexible specifications in the presence of omitted variables. As a robustness check on the sensitivity of our results to the choice of the log linear specification, we also estimated a $\log -\log$ model where all of the strictly positive variables were transformed using natural logs; that is, the arsenic variable multiplied by the year indicator variables were not logged. This had a negligible effect on the arsenic results reported in Table 2. For example, the arsenic interaction for Hollis in 1995 decreased in absolute magnitude from -0.0055 to -0.0052 , with no change in statistical significance. (Full results from the log-log model and other robustness checks described below are contained in a supplemental appendix provided on the first author's Web page.)

[44] The second caveat to our analysis concerns the implications of housing market adjustment. Recent research on household sorting behavior has stressed the difficulty in assessing the costs and benefits of changes in environmental quality when people are freely mobile [Epple and Sieg, 1999; Smith et al., 2004; Kuminoff, 2009]. Intuitively, the households who sold their homes in Buxton and Hollis between 1993 and 1995 may have chosen to move out of these communities partly due to a strong desire to reduce their exposure to arsenic. Likewise, the households who moved into the two towns may have been less worried about the future health consequences. This type of sorting behavior would imply that the drop in property values that we observed for Buxton in 1993 and 1994 and for Hollis in 1995 would understate the amount that the households who moved out of the two towns would be willing to pay to avoid the risks of arsenic exposure. Thus, the $0.5 \%$ to $1 \%$ decreases in property values that we observe are best interpreted as lower bounds on the willingness to pay to avoid arsenic exposure by the households who lived in the two towns at the beginning of our study period. That said, the cost of installing a point-of-use treatment system was only about $\$ 411$ at this time, which is likely much less than the cost of moving. Even a point-of-entry system for a whole house, at an installation cost of $\$ 5,000$ to $\$ 10,000$, may be less than the cost of moving. In addition, arsenic was also subsequently identified in communities neighboring Buxton and Hollis (e.g., neighboring Standish), and throughout the state of Maine, which may have diminished the desire to relocate. Given these considerations and the price stigma dissipating through time, the $0.5 \%$ to $1 \%$ decreases may not be substantial underestimates.

[45] The final caveat to our analysis concerns the limitations of our data. While our spatial error models provide an indirect control for spatial correlation in unobserved variables, we would also like to be able to directly control for more structural housing characteristics such as the number of bathrooms and whether the home has a fireplace, a basement, a garage or an in-home treatment system for arsenic. Unfortunately, these data are not collected or reported by the assessors in Buxton and Hollis. Following a suggestion from a referee, we tried adding quadratic functions of the observed structural characteristics to the model to help control for the effect of unobserved structural characteristics. Four additional terms were added: SQFT $^{2}$, $\mathrm{AGE}^{2}, \mathrm{ACRES}^{2}$, and AGE*SQFT. These terms will help to control for unobserved characteristics to the extent that they are correlated. For example, if newer homes tend to have more bathrooms and larger bedrooms, these unobserved characteristics will be correlated with AGE*SQFT. Adding the quadratic functions of observed characteristics to the Buxton and Hollis models increased their explanatory power slightly, as measured by the $\mathrm{R}^{2}$, by 0.01 for Buxton and by 0.008 for Hollis. However, it did not affect the magnitude of the arsenic coefficients or their statistical significance.

[46] The absence of a variable indicating an in-home treatment system is problematic because this variable is likely correlated with $a_{n}$. This means that sold properties with and without a home treatment system are treated the same in the estimation. If the presence of an in-home treatment system reduces price suppression, as we would expect, then treating sales of homes with and without these systems the same in our econometric model would cause us to underestimate willingness to pay. This reinforces our interpretation of the $0.5 \%$ to $1 \%$ decreases in property values as lower bounds on the willingness to pay to avoid arsenic exposure.

[47] It is also natural to be concerned about omitted environmental amenities. Unlike other recent hedonic studies of health risk [e.g., Davis, 2004], we do not have data on repeated sales of individual homes that would allow us to control for time-constant omitted amenities using parcel-specific fixed effects. If an amenity that matters to households is correlated with our measure for arsenic concentrations, it may confound our estimates for the property value effect of arsenic. However, in order for an omitted variable to bias our results, the omitted variable would have to be spatially correlated with arsenic concentrations and temporally correlated with the spread of information about arsenic findings. This seems unlikely. One reason is that arsenic concentrations tend to be patchy due to features of the underlying bedrock that have little to do with how the land above is utilized. Moreover, if an unobserved amenity were correlated with arsenic concentrations we would expect to see an effect on property values before the public learned about arsenic in well water. This is not the case. Our econometric results indicate that, after controlling for observed property characteristics, there were no significant differences in the prices of properties located in high-arsenic areas; that is, the coefficient on $\mathrm{T} 1992 * a_{n}$ is not statistically different from zero for Buxton.

[48] Finally, because many of the coefficients of the Buxton and Hollis models are not statistically different from each other, we estimated a pooled version of the model that combines the data from both towns, but allows the price effect of arsenic to differ across the two towns between 1993 and 1995. The results are reported in the third column of Table 2. For example, the coefficient on T1993* $a_{n}$ measures the baseline effect of arsenic for both towns in 1993 and the coefficient on T1993* $a_{n}{ }^{*}$ Buxton measure the deviation from this baseline for Buxton. While there are slight changes in the magnitudes of some of the coefficients, the overall pattern of results is the same as in the town-specific regressions. In short, arsenic levels above the MCL appear to have decreased property values in Buxton during 19931994 and appear to have decreased property values in Hollis during 1995.

[49] Overall, the pattern of results in Table 2 allows us to clearly reject the null hypothesis of a "permanent stigma" as 
illustrated in Figure 3. In addition, logical intuition suggests that the price decreases of $0.5 \%$ to $1 \%$ are lower-bound estimates on what households would be willing to pay to avoid arsenic exposure. However, the results do not allow us to distinguish between "no stigma" and "temporary stigma." Distinguishing between these two effects would require tracking whether the installation of home treatment systems over time matched the time path of the property value effect of arsenic. As noted earlier, data on the installation of home treatment systems are not currently collected or reported. Using household surveys to collect these data and investigate the empirical form of stigma would be an interesting direction for future research.

\section{Conclusion and Discussion}

[50] This paper has investigated the impact of arsenic contamination of groundwater on the markets for land and housing in the Maine towns of Buxton and Hollis. Media attention focused on these communities in 1993 and 1994 when $14 \%$ of private wells were found to have concentrations of arsenic that exceeded the EPA standard of $0.05 \mathrm{mg} / \mathrm{L}$. Our statistical results indicate that finding arsenic in drinking water led to significant, but temporary, decreases in property prices. Property prices rebounded three years after arsenic contamination became common knowledge.

[51] These findings imply that notification by the state of Maine, supported by media coverage, did have an effect on risk perceptions as revealed through lower sales prices of properties near arsenic test results that exceeded the MCL. In addition, the results suggest that a property-specific contamination incident that is treatable does not have a long-lasting effect on sale prices of residential properties. This suggests that long-term stigmas, such as those found by Kiel [1995], McCluskey and Rausser [2003], and Messer et al. [2006], may be unlikely outside of locations such as Superfund sites where all properties in an area are adversely affected to a greater or lesser degree and there is little that nearby households can do to reduce their level of exposure, other than move. In contrast, because arsenic is treatable, households can control their level of exposure by installing in-home treatment systems. The installation costs are absorbed by homeowners and the value of the installed systems is capitalized into the resale value of the homes.

[52] While the installation of in-home treatment systems helps to explain why arsenic did not permanently decrease property prices in Buxton and Hollis, the brief duration of the decrease is somewhat surprising. This may be at least partly explained by imperfect information and variation in subjective risk perceptions. For example, Shaw et al. [2005] find that only $38 \%$ of households with private wells treat their tap in Churchill County, Nevada despite the fact that the median arsenic concentration in the county is more than 5 times the EPA standard. The other $62 \%$ of households may be unaware that arsenic concentrations exceed the EPA standard, unaware that elevated arsenic levels pose a serious health risk, or may think that the risk is low for their household.

[53] An alternative, and complementary, explanation for why property prices rebounded so quickly in Buxton and Hollis is that once the flow of newspaper articles about these two towns stopped in 1995, potential homebuyers may have mistakenly assumed the danger had passed. For example,
Rogers [1997, p. 292] concludes “...that the social processes that construct and maintain [emphasis added] risk in the public eye are at least as important as, if not more important than, the physical and psychological dimension of risk." Studies by Brown and Schrader [1990] (cholesterol and heart disease linkages to egg consumption) and M. Neidell (Public information and avoidance behavior: Do people respond to smog alerts?, unpublished manuscript, 2006, available at http://econweb.tamu.edu/workshops/PERC\% 20Applied\%20Microeconomics/Matthew\%20Neidell.pdf) (smog alerts in southern California) found that public risk perceptions were affected through sustained and focused media programs. These findings are supported by experimental studies by Smith and Johnson [1988] and Smith et al. [1995], which found that targeted, prescriptive information about radon and in-home treatment affected risk perceptions. Thus, the lack of sustained, focused media attention likely did reduce the perceived risk of arsenic by some residents of Buxton and Hollis. The longer price effects of Superfund sites, therefore, may be due to risks that households cannot control and sustained media attention on these sites over many years.

[54] Important directions for future research include investigating whether potential homebuyers' subjective risk perceptions about arsenic exposure and the reliability of treatment systems are consistent with the scientific evidence. In addition, studies of different areas and applications can reveal whether the short-term price suppression that occurs for other risks is due to the risk being treatable by household mitigation actions, or is due to media attention on the risks being limited in time, or a combination of both.

[55] In the current situation the significant, short-term price effect clearly indicates that the state of Maine's notification of arsenic risks in drinking water in the communities of Buxton and Hollis, supported by media coverage, had a nearly immediate effect, but this research does not indicate if all households who have arsenic concentrations in excess of $0.05 \mathrm{mg} / \mathrm{L}$ in their tap water took action to protect their family members from the risks of exposure. A follow-up investigation is clearly warranted to confirm whether all households at risk did in fact take remediation actions to mitigate exposure to arsenic in their tap water.

[56] Acknowledgments. This research was funded by the U.S. Environmental Protection Agency, the Virginia Agricultural Experiment Station, and the Maine Agricultural and Forest Experiment Station. The authors would like to thank Andrew Smith, Maine toxicologist, for his assistance in understanding arsenic in drinking water.

\section{References}

Ahmad, J., B. Goldar, and S. Misra (2005), Value of arsenic-free drinking water to rural households in Bangladesh, J. Environ. Manage., 74(2), 173-185, doi:10.1016/j.jenvman.2004.07.011.

Anselin, L. (1988), Spatial Econometrics: Methods and Models, Kluwer Acad., Dordrecht, Netherlands.

Anselin, L. (2002), Under the hood: Issues in the specification and interpretation of spatial regression models, Agric. Econ., 27(3), 247-267, doi:10.1111/j.1574-0862.2002.tb00120.x.

Boyle, K. J., G. L. Poe, and J. C. Bergstrom (1994), What do we know about groundwater values? Preliminary implications from a meta analysis of contingent valuation studies, Am. J. Agric. Econ., 76(5), 10551061, doi:10.2307/1243391.

Boyle, M. A., and K. A. Kiel (2001), A survey of house price hedonic studies of the impact of environmental externalities, J. Real Estate Lit., 9(2), $117-144$. 
Brown, D. J., and L. F. Schrader (1990), Cholesterol information and shell egg consumption, Am. J. Agric. Econ., 72(3), 548-555, doi:10.2307/ 1243023.

Cropper, M. L., L. B. Deck, and K. E. McConnell (1988), On the choice of functional form for hedonic price functions, Rev. Econ. Stat., 70(4), 668675, doi: $10.2307 / 1935831$

Davis, L. (2004), The effect of health risk on housing values: Evidence from a cancer cluster, Am. Econ. Rev., 94(5), 1693-1704, doi:10.1257/ 0002828043052358.

Ekeland, I., J. J. Heckman, and L. Nesheim (2004), Identification and estimation of hedonic models, J. Polit. Econ., 112(S1), S60-S109, doi:10.1086/379947.

Epple, D., and H. Sieg (1999), Estimating equilibrium models of local jurisdiction, J. Polit. Econ., 107(4), 645-681, doi:10.1086/250074.

Jakus, P. M., W. D. Shaw, N. Nguyen, and M. Walker (2009), Risk perceptions of arsenic in tap water and consumption of bottled water, Water Resour. Res., 45, W05405, doi:10.1029/2008WR007427.

Kiel, K. A. (1995), Measuring the impact of the discovery and cleaning of identified hazardous waste sites on house values, Land Econ., 71(4), 428-435, doi: $10.2307 / 3146708$.

Kuminoff, N. V. (2009), Decomposing the structural identification of nonmarket values, J. Environ. Econ. Manage., 57(2), 123-139, doi:10.1016/ j.jeem.2008.07.003.

Lancaster, K. J. (1966), A new approach to consumer theory, J. Polit. Econ., 74(2), 132-157, doi:10.1086/259131.

Maddison, D., R. Catala-Luque, and D. Pearce (2005), Valuing the arsenic contamination of groundwater in Bangladesh, Environ. Resour. Econ., 31(4), 459-476, doi:10.1007/s10640-005-3364-z.

Maine Department of Professional and Financial Regulation (2006), Minimum standards of practice, 10 pp., 02, 039, Chap. 410, 15, Real Estate Comm., Augusta. (Available at http://www.maine.gov/sos/cec/rules/02/ 039/039c410.doc)

Maine Geological Survey (2005), Pesticides, arsenic, and radon in ground water, Maine Dep. of Conserv., Augusta. (Available at www.maine.gov/ doc/nrimc/mgs/about/water-pest.htm)

Malone, P., and R. L. Barrows (1990), Groundwater pollution's effects on residential property values, Portage County, Wisconsin, J. Soil Water Conserv., 45(2), 346-348.

Marvinney, R., M. Loiselle, J. Hopeck, D. Braley, and J. Krueger (1994), Arsenic in Maine groundwater: An example from Buxton Maine, paper presented at Focus Conference on Eastern Regional Ground Water Issues, Natl. Ground Water Assoc., Burlington, Vt.

McCluskey, J. J., and G. C. Rausser (2003), Stigmatized asset value: Is it temporary or long-term?, Rev. Econ. Stat., 85(2), 276-285, doi:10.1162/ 003465303765299800

Messer, K. D., W. D. Schulze, K. F. Hackett, T. A. Cameron, and G. H. McClelland (2006), Can stigma explain large property value losses? The psychology and economics of Superfund, Environ. Resour. Econ., 33(3), 299-324, doi:10.1007/s10640-005-3609-x.

Poe, G. L., and R. C. Bishop (1999), Valuing the incremental benefits of groundwater protection when exposure levels are known, Environ. Resour. Econ., 13(3), 341-367, doi:10.1023/A:1008251418007.

Rogers, G. O. (1997), The dynamics of risk perception: How does perceived risk respond to risk events?, Insurance Math. Econ., 22(3), 292.

Rosen, S. (1974), Hedonic prices and implicit markets: Product differentiation in pure competition, J. Polit. Econ., 82(1), 34-55, doi:10.1086/ 260169.

Roy, J. (2008), Economic benefits of arsenic removal from ground water-A case study from West Bengal, India, Sci. Total Environ., 397(1-3), 1-12, doi:10.1016/j.scitotenv.2008.02.007.

Sargent-Michaud, J., K. J. Boyle, and A. E. Smith (2006), Cost effective arsenic reductions in private well water in Maine, J. Am. Water Resour. Assoc., 42(5), 1237-1245.
Shaw, W. D., M. Walker, and M. Benson (2005), Treating and drinking well water in the presence of health risks from arsenic contamination: Results from a U.S. hot spot, Risk Anal., 25(6), 1531-1543, doi:10.1111/j.1539-6924.2005.00698.x.

Smith, A. H., M. Goycolea, R. Haque, and M. L. Biggs (1998), Marked increase in bladder and lung cancer mortality in a region of northern Chile due to arsenic in drinking water, Am. J. Epidemiol., 147(7), 660-669.

Smith, A. H., M. L. Biggs, L. E. Moore, R. Haque, C. Steinmaus, J. Chung, A. L. Hernandez, and P. Lopipero (1999), Cancer risks from arsenic in drinking water: Implications for drinking water standards, in Arsenic Exposure and Health Effects: Proceedings of the Third International Conference on Arsenic Exposure and Health Effects, July 12-15, 1998, edited by W. Chappell et al., pp. 191-199, Elsevier Sci., Oxford, U. K.

Smith, V. K., and F. R. Johnson (1988), How do risk perceptions respond to information? The case of radon, Rev. Econ. Stat., 70(1), 1-8, doi:10.2307/1928144.

Smith, V. K., W. H. Desvousges, and J. W. Payne (1995), Do risk information programs promote mitigating behavior?, J. Risk Uncertainty, 10(3), 203-221, doi:10.1007/BF01207551.

Smith, V. K., H. Sieg, H. S. Banzhaf, and R. Walsh (2004), General equilibrium benefits for environmental improvements: Projected ozone reductions under EPA's prospective analysis for the Los Angeles air basin, J. Environ. Econ. Manage., 47(3), 559-584, doi:10.1016/j. jeem.2003.10.006

Stevens, T. H., C. Barrett, and C. E. Willis (1997), Conjoint analysis of groundwater protection programs, Agric. Resour. Econ. Rev., 26(2), 229-236.

U.S. Environmental Protection Agency (EPA) (2001), National primary drinking water regulations; arsenic and clarifications to compliance and new source contaminants monitoring, final rule, FR Doc. 01-1668, pp. 6975-7066, Washington, D. C. (Available at www.epa.gov/ fedrgstr/EPA-WATER/2001/January/Day-22/w1668.htm)

U.S. Environmental Protection Agency (EPA) (2005), Water health series: Filtration facts, Rep. 816-K-05-002, Washington, D. C. (Available at http://www.epa.gov/safewater/faq/pdfs/fs_healthseries_filtration.pdf)

Walker, M., W. D. Shaw, and M. Benson (2005), Significance of private water supply wells as a route of exposure to aqueous arsenic, J. Water Health, 3(3), 305-312.

Walker, M., W. D. Shaw, and M. Benson (2006), Arsenic consumption and health risk perceptions in a rural western U.S. area, J. Am. Water Resour. Assoc., 42(5), 1363-1370.

World Health Organization (WHO) (2001), Arsenic in drinking water, fact sheet, WHO Media Centre, Geneva, Switzerland. (Available at http:// www.epa.gov/safewater/faq/pdfs/fs_healthseries_filtration.pdf)

Zierold, K. M., L. Knobeloch, and H. Anderson (2004), Prevalence of chronic diseases in adults exposed to arsenic-contaminated drinking water, Am. J. Public Health, 94(11), 1936-1937, doi:10.2105/ AJPH.94.11.1936.

K. P. Bell, School of Economics, University of Maine, 5782 Winslow Hall, Orono, ME 04469, USA.

K. J. Boyle and C. Zhang, Department of Agricultural and Applied Economics, Virginia Polytechnic Institute and State University, 208A Hutcheson Hall, Blacksburg, VA 24061, USA.

M. Devanney, Nova Scotia Department of Agriculture, PO Box 550, Truro, NS B2N 5E3, Canada.

N. V. Kuminoff, Department of Economics, Arizona State University, PO Box 873806, Tempe, AZ 85287, USA. (kuminoff@asu.edu) 